\title{
Reply to Letter to the Editor: Ultrasound-Guided Percutaneous Long Head of the Biceps Tenotomy
}

\author{
Harry G. Greditzer IV MD, MS(R) • Jean Jose, DO, MS
}

Received: 3 October 2014/Accepted: 10 November 2014/Published online: 30 January 2015

(C) Hospital for Special Surgery 2015

The recent publication by Aly et al. [1] further confirms our conclusion that ultrasound-guided percutaneous tenotomy of the long head of the biceps tendon is feasible. Our paper was accepted for publication in April 2014 [2], and the Aly et al. paper was accepted for publication in June 2014. Since we had no previous knowledge of their study, we could not reference it in our paper. However, they describe a similar technique and results to ours using an arthroscopic hook blade, with a deep to superficial approach in the cadavers, which successfully resulted in complete tendon transection and no evidence of iatrogenic injury. We are the first to describe this procedure successfully performed on a live subject. Both the Aly et al. and the Levy et al. [3] studies show that the use of size 11 blade scalpels, banana blades, and retractable serrated blades results in incomplete transections of the tendons, as well as iatrogenic lesions of the cartilage, supraspinatus tendon, and subscapularis tendon. This further supports our conclusion that hook blades are the ideal instruments to obtain

Electronic supplementary material The online version of this article (doi:10.1007/s11420-014-9427-3) contains supplementary material, which is available to authorized users.

H. G. Greditzer, IV, MD, MS(R) $(\varangle) \cdot J$ J. Jose, DO, MS

UHealth Sports Performance and Wellness Institute,

Department of Orthopaedics,

University of Miami Miller School of Medicine,

Miami, FL, USA

e-mail: Tategred@gmail.com

Present Address

H. G. Greditzer, IV, MD, MS(R)

Hospital for Special Surgery,

535 East 70th Street,

New York, NY 10021 successful results of complete tendon transection, without iatrogenic injury. We concur that future long-term comparative studies of US-guided percutaneous tenotomy procedures are necessary to determine the efficacy of the procedure.

\section{Disclosures}

Conflict of Interest: Harry G. Greditzer, IV, MD, MS(R) and Jean Jose, DO, MS have declared that they have no conflict of interest.

Human/Animal Rights: This article does not contain any studies with human or animal subjects performed by the any of the authors.

\section{Informed Consent: N/A}

Required Author Forms Disclosure forms provided by the authors are available with the online version of this article.

\section{References}

1. Aly AR, Rajasekaran S, Mohamed A, et al. Feasibility of ultrasound-guided percutaneous tenotomy of the long head of the biceps tendon-A pilot cadaveric study. J Clin Ultrasound. 2014. doi:10.1002/jcu.22189.

2. Greditzer HG 4th, Kaplan LD, Lesniak BP, et al. Ultrasound guided percutaneous long head of the biceps tenotomy: a novel technique with case report. HSS J. 2014; 10(3): 240-4.

3. Lévy B, Ducat A, Gaudin P, et al. Ultrasound-guided percutaneous tenotomy of the long head of the biceps tendon: a Blinded Manuscript: a non-reliable technique. Knee Surg Sports Traumatol Arthrosc. 2012; 20(6): 1027-30. 